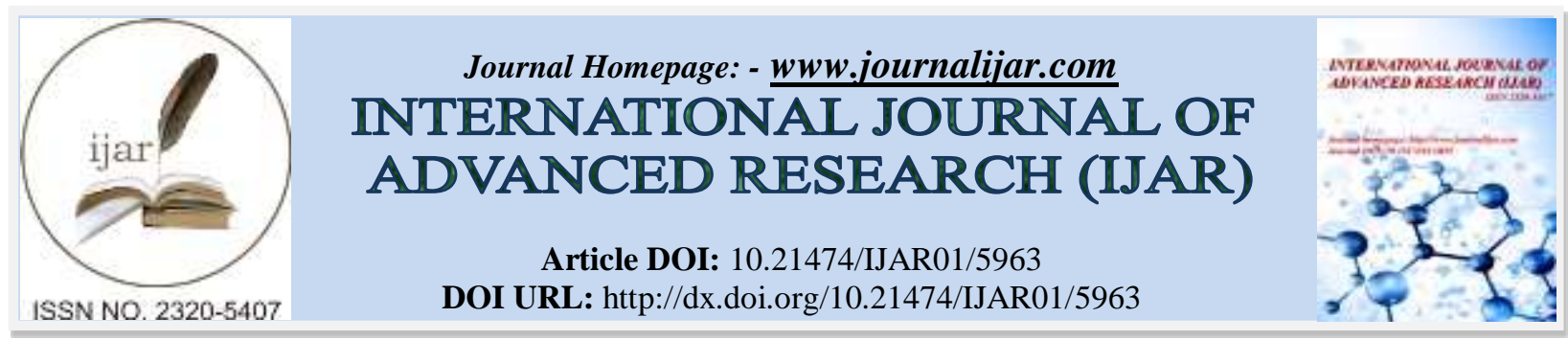

RESEARCH ARTICLE

\title{
MATERNAL RISK FACTORS ASSOCIATED WITH AUTISM AMONG CHILDREN IN JEDDAH AUTISM CENTER, SAUDI ARABIA, JEDDAH 2016: A CASE-CONTROL STUDY.
}

\section{Samera A. Mugharbil ${ }^{1}$, Jawaher R. Alahmadi ${ }^{2}$ and Adel M. Ibrahim ${ }^{3}$.}

1. MBBS, Family Medicine Resident, Ministry of Health, Jeddah, Saudi Arabia.

2. SBFM, ABFM, MSc, Consultant Family Physician, Department Of Community And Family Medicine, King Abdul azziz University, Jeddah, Saudi Arabia.

3. MD, MDPH, Consultant Of Community Medicine, Ministry Of Health, Directorate Of Primary Health Care, Jeddah, Saudi Arabia.

\section{Manuscript Info}

\section{Manuscript History}

Received: 04 October 2017

Final Accepted: 06 November 2017

Published: December 2017

Key words:-

Autism, case control study, risk factors, Jeddah.

\begin{abstract}
Background: Autism is a lifelong neurodevelopment disorder associated with impairment of social communication and abnormal response to some environment stimuli.

The aim: Determining maternal risk factors associated with autism and help in prevention, early detection, and intervention.

Methodology: A case-control study design comprised all autistic children aged 3-6 years registered at Jeddah Autism Center during October 2016 (No. 27). With 1:3 ratio, eighty-one non-autistic controls attending kindergartens, age and sex-matched to autistic children were included in the study. Paper-based Arabic questionnaire was designed for the study.

Results: Most patients were males, mainly diagnosed at age of $3-<4$ years. Most of their parents were highly educated, with monthly income between 5000-10000 SAR. Positive family history of autism was more significant among cases than controls $(\mathrm{p}<0.05$, OR;9.017, 95\% CI:3.550-23.363). Cases were born for mothers aged $\geq 30$ years and fathers aged $\geq 40$ years more than controls. Parents consanguinity, post-term delivery, macrosomia and fetal distress during labor were more among cases. A lower percentage of cases were discharged from the hospitals with their mothers after delivery, as well as exclusively breastfed. Significantly more cases had neonatal jaundice than controls ( $<<0.05$, OR;3.250, 95\% CI:1.275-8.284).

Conclusions: Incidence of autism in Jeddah is higher among males who are diagnosed mainly between age of 3-4 years. Some characteristics are associated with cases of autism. However, differences are significant to a positive family history of autism and occurrence of neonatal jaundice.
\end{abstract}

Copy Right, IJAR, 2017,. All rights reserved. 


\section{Introduction:-}

Autism is a chronic neurodevelopment disorder characterized by an inability to communicate socially or to respond normally to some stimuli in the environment. A systematic review done to estimate the global effect of autism in 188 countries showed that autism affects about 21.7 million people as of 2013. (1)

According to the Center for Disease Control and Prevention, about 1 in 68 children has been estimated to have autism in U.S It occurs five times more prevalent in boys than girls. (2)

The etiology of autism is unknown, but several different factors that make a child more likely to have autism include biological and environmental factors. The genetic factors play a significant role in the disease. However, the presence of environmental risk factors can interact with these genetic factors and increase the possibility of occurrence of the disease. (3)(4)

Evidence suggests that the critical period for developing autism occurs before, during, and immediately after birth. A meta-analysis did at the Department of Epidemiology, Harvard School of Public Health, examined over 60 perinatal and neonatal factors and found an association with some of these factors. (5)

Another systematic review summarized the pre, peri and neonatal risk factors that contribute to autism, and conclude that these factors may have a small risk for autism. However, the distinction was not possible if these risks should be considered purely environmental or relevant to genetic vulnerability. (6)

A case-control study in Jamaica concluded that maternal and paternal ages were associated with autism. Prematurity, low birth weight and small for gestational age are other risk factors for autism determine in research. (7) These factors were found to be associated with autism in a case-control study conducted in Finland. (8) Furthermore, a case-control study carried out in China, identified nine maternal risk factors that revealed a significant association with autism. (9)

In addition, several maternal lifestyle factors such as nutrition and substance use can be related to many neurodevelopment diseases and therefore, may not be unique risk factors for autism. (10)

A systematic review on epidemiology of autism concluded that there are limitations in research and no studies on identifying the burden and risk factors of autism in Gulf countries. (11)

In Oman, a case-control study about the relation between breastfeeding and autism concluded that the risk of autism increases with delayed breastfeeding and no colostrum introduction, while exclusive breastfeeding and its continuation for two years significantly decrease the risk. (12)

Most studies in Saudi Arabia on autism focused on biomarker studies as risk factors. A cross-sectional study done on 49 autistic children found that the communication problem is the most characteristic of an autistic patient with the presence of consanguineous marriages in approximately $29 \%$. (13)

Several diagnostic tests make an early diagnosis of autism by the age of 2 years very reliable. However, many cases do not reach final diagnosis until an age of 3 years. Currently, no cure for autism but research shows that early interventions treatment services up to 3 years can improve and increase the quality of life and functional independence. (2)

The early diagnosis and early intensive treatment have the potential to affect the outcome. (14) The diagnosis of autism can be made clinically, based on the history, examination, and observation of behavior. The establishment of appropriate management strategies in the early years can help to minimize or even avoid subsequent behavioral problems. (15)

With increasing autism prevalence worldwide, there is a need for more research to understand the disease, risk factors, diagnosis, and management. Therefore, this study aimed to identify risk factors associated with autism and help in prevention, early detection, and intervention. 


\section{Methodology:-}

Following a case-control design, this study was conducted during October 2016. It included all autistic children aged 3-6 years registered at Jeddah Autism Center (No. 27). Moreover, 81 non-autistic children, age and sexmatched to autistic children were included as control subjects who were recruited from Al Nasifiah private school and kindergarten-19 public school in Jeddah, Saudi Arabia.

A specific paper-based self-administered Arabic language questionnaire was designed for this study by the researchers, which has been validated by three consultants (i.e., a psychologist, an epidemiologist, and a family medicine consultant). The questionnaire included demographic data of parents and subjects, as well as pre, peri and neonatal risk factors that may be associated with autism. The Fifth Diagnostic and Statistical Manual of Mental Disorders (DSM-V), paper-based and Arabic version criteria, were used as a tool for screening for the control group. However, none of them showed any sign of being autistic.

During parents' meetings, the self-administered questionnaire sheets were distributed and filled by the subject's parents after obtaining written consent from them.

The research started with data collection after fulfilling all necessary official approvals from committee of the joint program of family medicine in Jeddah City, higher authority (Ministry of Education) approvals, and local institutional departments.

For data entry and statistical analysis, the researchers used the Statistical Package for Social Sciences (SPSS, version $21)$. Descriptive statistics (frequencies and percentages) were applied. The Chi-squared $\left(\chi^{2}\right)$ test was applied to test the significance of differences between study and control groups. Fisher exact test was applied if more than $25 \%$ of expected values were less than 5 . P-values less than 0.05 were considered as statistically significant.

\section{Results:-}

Table 1 shows that the majority of the cases or patients (77.8\%) are males. Almost all children are Saudis. Most of the patients are living in families with highly educated mothers having university qualification $(51.9 \%)$ and much more in the controls group (82.8\%) and highly educated fathers also having university qualification (55.6\%) in comparing to $(76.6 \%)$ of the controls group. Although that, the majority $(70.4 \%)$ of the case's mothers were not working, all the fathers were working except two (7.4\%) who were retired. On the other hand, more than half mothers of the controls group (58.0\%) were working, and most fathers $(96.3 \%)$ were working while two of the three non-working fathers were retired. The monthly income ranging between 5000-<10000 SR (59.3\%) in the cases group in comparing to $10000-<20000$ SR $(58.0 \%)$ in the controls group. Slightly less than one-half of the patients (44.4\%) have one sibling while only one-quarter of the control children (24.7\%) have one sibling, and mainly (48.1\%) of the patients are the third or more with in their brothers and sisters in comparing to $(45.6 \%)$ of the controls group.

The study figured that almost one-half of the cases (48.2\%) were diagnosed at the age of 3 to $<4$ years, and $37 \%$ who were diagnosed at a younger age 2 to $<3$ years as shown on figure 1 .

Table 2 shows that positive family history of autism was significantly more prevalent in the cases $(29.6 \%)$ than control $(6.2 \%) \mathrm{p}<0.05$, with an odds ratio (OR; 9.017, 95\% CI: 3.550-23.363). In cases, two histories were brothers, and six histories were cosines. While in control, one history was a brother, and six histories were cosines. Meanwhile, the table demonstrates that, although consanguinity of the parents was remarkably more frequent in autistic patients $(37 \%)$ than control $(27.2 \%)$, this difference is not statistically significant. Meanwhile, it was observed that the great majority of the surveyed children were living with their parents, with no statistically significant differences between the cases and controls. The table also demonstrates that a larger percentage (44.4\%) of the cases were born for relatively older mothers (Aged $\geq 30$ years) compared to $38.3 \%$ of the controls, in the same context, a higher percentage of the cases were born to relatively older fathers aged more than 40 years (33.3\%) than controls $(23.5 \%)$. Nevertheless, these differences are not statistically significant.

Compared to the mothers of the control children, almost double of the mothers of the cases (14.8\%) reported that they had been suffering from diseases such as diabetes mellitus, hypertension, and hypothyroidism before pregnancy of the examined child [Table 3]. Also, a higher percentage (14.4\%) of the mothers of the cases than control (4.9\%) 
expressed that they had gestational diabetes during pregnancy, with more frequency of preeclampsia (7.4\%) and hypothyroidism during pregnancy $(2.5 \%)$ if compared to the mothers of the controls (1.2\% and $2.5 \%$ respectively). However, no statistical significance for these differences. A slightly higher percentage of the mothers of the cases exposed to passive smoking (33.3\%) than controls $(28.4 \%)$. On the other hand, a lower percentage of the mothers of the cases $(3.7 \%)$ than controls $(8.6 \%)$ addressed that they had used non-prescribed drugs (paracetamol according to all mothers) while they were pregnant, but this difference is also not statistically significant. Among controls, only one mother indicated that she had psychological problems (depression) during pregnancy with no statistically significant difference between cases and controls.

Most of the cases (70.4\%) and almost two thirds of the controls (64.2\%) were delivered by vaginal delivery, with a minority of both whom delivery required ventouse (5.3\% for cases and 5.8\% for controls) or who received epidural analgesics (10.5\% for cases and $15.7 \%$ for controls). Regarding the mothers who underwent Cesarean sections, although the percentage of those who received general anesthesia was higher in mothers of cases (75\%) than controls, this difference is not statistically significant [Table 4]. Moreover, a slightly higher percentage of the cases were post-term $(25.9 \%)$ than controls $(13.8 \%)$, which is not statistically significant, and remarkably higher percentage of them (14.8\%) suffered from fetal distress during labor if compared to controls (3.7\%) with a borderline significance at $\mathrm{p}=0.06$.

At delivery, as demonstrated in Table 5, a greater percentage of the cases $(22.2 \%)$ than controls $(9.9 \%)$ had a birth weight $>3.5 \mathrm{~kg}$ with only one of the cases $(5.3 \%)$ who was breech which is not statistically significant. Almost equal percentages of the cases $(14.8 \%)$ and controls $(12.3 \%)$ needed ICU services for different reasons. Although that a lower percentage of the cases $(77.8 \%)$ than controls $(86.4 \%)$ were discharged from the hospitals with their mothers, and a lower percentage of them (14.8\%) than controls $(24.7 \%)$ who had been exclusively breast feed, these differences are not statistically significant.

On the same context, Figure 2 illustrates that the percentage of those who had neonatal jaundice was significantly higher in cases $(44.4 \%)$ than controls $(19.8 \%) \mathrm{p}<0.05$, with an odds ratio (OR, 3.250, 95\% CI: 1.275-8.284).

Table 1:- Demographic Characteristics of The Children.

\begin{tabular}{|c|c|c|c|c|}
\hline \multirow{3}{*}{ Characteristics } & \multicolumn{4}{|c|}{ Study group } \\
\hline & \multicolumn{2}{|c|}{ Cases } & \multicolumn{2}{|c|}{ Controls } \\
\hline & No & $\%$ & No & $\%$ \\
\hline \multicolumn{5}{|l|}{ Gender: } \\
\hline Male & 21 & 77.8 & 63 & 64 \\
\hline Female & 6 & 22.2 & 18 & 22.2 \\
\hline \multicolumn{5}{|l|}{ Age: } \\
\hline $3-<4$ years & 3 & 11.1 & 9 & 11.1 \\
\hline $4-<5$ years & 9 & 33.3 & 27 & 33.3 \\
\hline $5-<6$ years & 15 & 55.6 & 45 & 55.6 \\
\hline \multicolumn{5}{|l|}{ Nationality: } \\
\hline Saudi & 26 & 96.3 & 77 & 95.1 \\
\hline Non-Saudi & 1 & 3.7 & 4 & 4.9 \\
\hline \multicolumn{5}{|c|}{ Education level of the mother: } \\
\hline Illiterate & 2 & 7.4 & 1 & 1.2 \\
\hline School level & 11 & 40.7 & 13 & 16 \\
\hline University & 14 & 51.9 & 67 & 82.8 \\
\hline \multicolumn{5}{|c|}{ Education level of the Father: } \\
\hline Illiterate & 1 & 3.7 & 1 & 1.2 \\
\hline School level & 11 & 40.7 & 18 & 22.2 \\
\hline University & 15 & 55.6 & 62 & 76.6 \\
\hline \multicolumn{5}{|l|}{ Working Mother: } \\
\hline Yes & 8 & 29.6 & 47 & 58 \\
\hline No & 19 & 70.4 & 34 & 42 \\
\hline \multicolumn{5}{|l|}{ Working Father: } \\
\hline Yes & 25 & 92.6 & 78 & 96.3 \\
\hline
\end{tabular}




\begin{tabular}{|l|c|c|c|c|}
\hline No & 2 & 7.4 & 3 & 3.7 \\
\hline Monthly income: & & & & 4 \\
\hline$<5000$ SR & 4 & 14.8 & 4 & 4.9 \\
\hline $5000-<10000$ SR & 16 & 59.3 & 16 & 19.8 \\
\hline $10000-<20000$ SR & 6 & 22.2 & 47 & 58.0 \\
\hline$\geq 20000$ SR & 1 & 3.7 & 14 & 17.3 \\
\hline Number of siblings: & & & & \\
\hline$\quad$ No sibling & & & 11 & 13.6 \\
\hline One & 12 & 44.4 & 20 & 24.7 \\
\hline $2-3$ & 7 & 25.9 & 30 & 37.0 \\
\hline$>3$ & 8 & 29.6 & 20 & 24.7 \\
\hline Order of the child: & & & & \\
\hline First & 11 & 40.7 & 28 & 34.6 \\
\hline Second & 3 & 11.1 & 16 & 19.8 \\
\hline Third or more & 13 & 48.1 & 37 & 45.6 \\
\hline
\end{tabular}

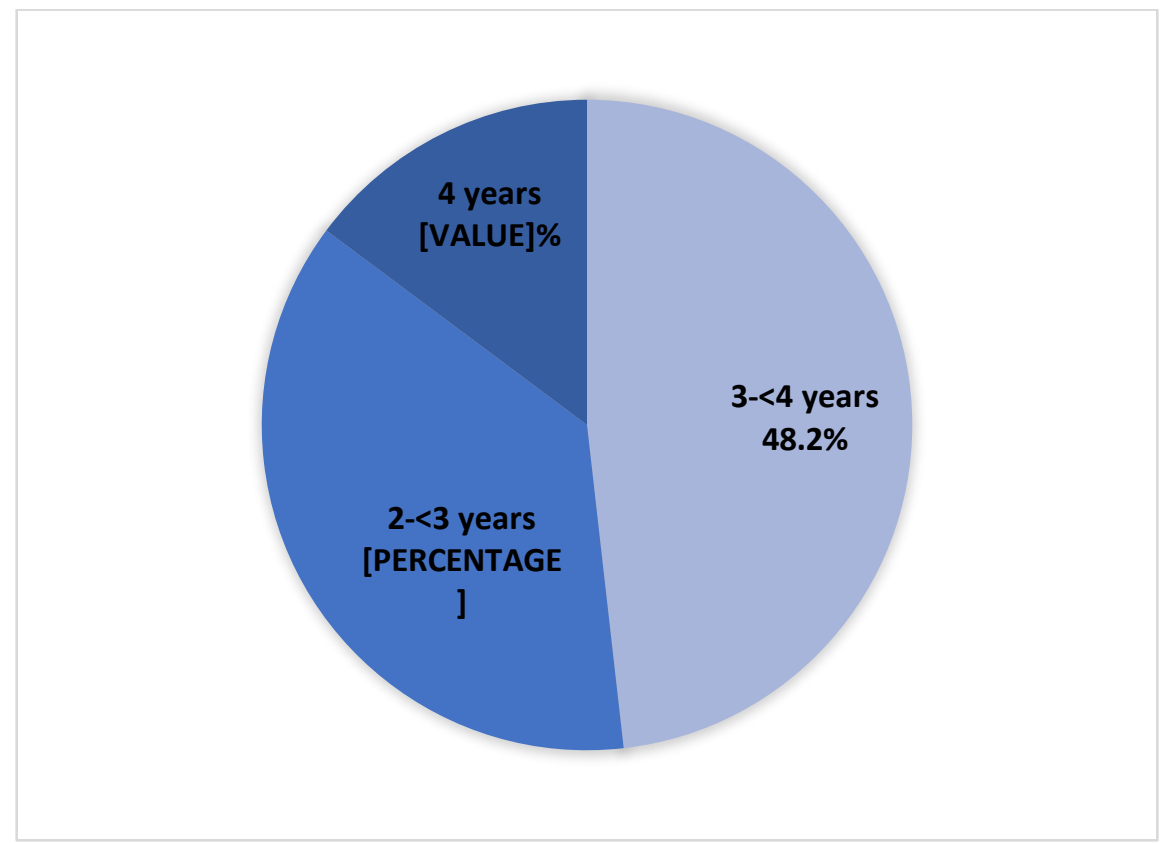

Figure 1:- Age at diagnosis of autism

Table 2:- Social and familial characteristics possibly associated with autism

\begin{tabular}{|c|c|c|c|c|c|c|}
\hline \multirow{3}{*}{ Characteristics } & \multicolumn{4}{|c|}{ Study group } & \multirow{3}{*}{$X^{2}$} & \multirow{3}{*}{$\mathrm{P}^{*}$} \\
\hline & \multicolumn{2}{|c|}{ Cases } & \multicolumn{2}{|c|}{ Controls } & & \\
\hline & No & $\%$ & No & $\%$ & & \\
\hline \multicolumn{5}{|c|}{ Consanguinity of the parents: } & \multirow[b]{3}{*}{0.947} & \multirow[b]{3}{*}{0.330} \\
\hline Yes & 10 & $37.0 \%$ & 22 & $27.2 \%$ & & \\
\hline No & 17 & $63.0 \%$ & 59 & $72.8 \%$ & & \\
\hline \multicolumn{5}{|c|}{ The child lives with parents: } & \multirow[b]{3}{*}{ Fisher } & \multirow[b]{3}{*}{0.170} \\
\hline Yes & 26 & $96.3 \%$ & 77 & $95.1 \%$ & & \\
\hline No & 1 & $3.7 \%$ & 4 & $4.9 \%$ & & \\
\hline \multicolumn{5}{|l|}{ Family history of autism: } & \multirow[b]{3}{*}{ Fisher } & \multirow[b]{3}{*}{$0.003 * *$} \\
\hline Yes & 8 & $29.6 \%$ & 5 & $6.2 \%$ & & \\
\hline No & 19 & $70.4 \%$ & 76 & $93.8 \%$ & & \\
\hline \multicolumn{5}{|l|}{$\begin{array}{l}\text { Psychological problems } \\
\text { among siblings: }\end{array}$} & \multirow[b]{2}{*}{ Fisher } & \multirow[b]{2}{*}{0.633} \\
\hline Yes & 1 & $3.7 \%$ & 1 & $1.2 \%$ & & \\
\hline
\end{tabular}




\begin{tabular}{|c|c|c|c|c|c|c|}
\hline No & 26 & $96.3 \%$ & 80 & $98.8 \%$ & & \\
\hline $\begin{array}{l}\text { Age of the m } \\
\text { pregnancy: }\end{array}$ & & & & & \multirow[b]{3}{*}{0.322} & \multirow[b]{3}{*}{0.570} \\
\hline$<30$ years & 15 & $55.6 \%$ & 50 & $61.7 \%$ & & \\
\hline$\geq 30$ years & 12 & $44.4 \%$ & 31 & $38.3 \%$ & & \\
\hline $\begin{array}{l}\text { Age of the fo } \\
\text { pregnancy: }\end{array}$ & & & & & \multirow{4}{*}{1.055} & \multirow{4}{*}{0.590} \\
\hline$<30$ years & 6 & $22.2 \%$ & 22 & $27.2 \%$ & & \\
\hline $30-40$ years & 12 & $44.4 \%$ & 40 & $49.4 \%$ & & \\
\hline$>40$ years & 9 & $33.3 \%$ & 19 & $23.5 \%$ & & \\
\hline
\end{tabular}

* Based on Chi Square ** Statistically significant

Table 3:- Prenatal an antenatal factors possibly associated with autism

\begin{tabular}{|c|c|c|c|c|c|c|}
\hline \multirow{3}{*}{ Characteristics } & \multicolumn{4}{|c|}{ Study group } & \multirow{3}{*}{$X^{2}$} & \multirow{3}{*}{$\mathrm{P}^{*}$} \\
\hline & \multicolumn{2}{|c|}{ Cases } & \multicolumn{2}{|c|}{ Controls } & & \\
\hline & No & $\%$ & No & $\%$ & & \\
\hline \multicolumn{5}{|c|}{ Prenatal health problems: } & \multirow[b]{3}{*}{ Fisher } & \multirow[b]{3}{*}{0.215} \\
\hline Yes & 4 & $14.8 \%$ & 6 & $7.4 \%$ & & \\
\hline No & 23 & $85.2 \%$ & 75 & $92.6 \%$ & & \\
\hline \multicolumn{5}{|c|}{ Gestational diabetes: } & \multirow[b]{3}{*}{ Fisher } & \multirow[b]{3}{*}{0.105} \\
\hline Yes & 4 & $14.8 \%$ & 4 & $4.9 \%$ & & \\
\hline No & 23 & $85.2 \%$ & 77 & $95.1 \%$ & & \\
\hline \multicolumn{5}{|l|}{ Preeclampsia: } & \multirow[b]{3}{*}{ Fisher } & \multirow[b]{3}{*}{0.154} \\
\hline Yes & 2 & $7.4 \%$ & 1 & $1.2 \%$ & & \\
\hline No & 25 & $92.6 \%$ & 80 & $98.8 \%$ & & \\
\hline \multicolumn{5}{|c|}{ Hypothyroidism during pregnancy: } & \multirow[b]{3}{*}{ Fisher } & \multirow[b]{3}{*}{0.750} \\
\hline Yes & 2 & $7.4 \%$ & 2 & $2.5 \%$ & & \\
\hline No & 25 & $92.6 \%$ & 79 & $97.5 \%$ & & \\
\hline \multicolumn{5}{|c|}{ Exposure to smoking during pregnancy: } & \multirow{4}{*}{ NA } & \\
\hline Smoker & 0 & $0.0 \%$ & 4 & $4.9 \%$ & & \\
\hline Passive smoker & 9 & $33.3 \%$ & 23 & $28.4 \%$ & & \\
\hline Not at all & 18 & $66.7 \%$ & 54 & $66.7 \%$ & & \\
\hline \multicolumn{5}{|c|}{ Took non-prescribed drugs during pregnancy: } & \multirow[b]{3}{*}{ Fisher } & \multirow[b]{3}{*}{0.358} \\
\hline Yes & 1 & $3.7 \%$ & 7 & $8.6 \%$ & & \\
\hline No & 26 & $96.3 \%$ & 74 & $91.4 \%$ & & \\
\hline \multicolumn{5}{|c|}{ Psychological problems: } & \multirow{3}{*}{ Fisher } & \multirow{3}{*}{0.154} \\
\hline Yes & 0 & $0.0 \%$ & 1 & $1.2 \%$ & & \\
\hline No & 27 & $100 \%$ & 80 & $98.8 \%$ & & \\
\hline \multicolumn{5}{|c|}{ Anemia during pregnancy: } & \multirow[b]{3}{*}{0.018} & \multirow[b]{3}{*}{0.892} \\
\hline Yes & 6 & $22.2 \%$ & 17 & $21.0 \%$ & & \\
\hline No & 21 & $77.8 \%$ & 64 & $79.0 \%$ & & \\
\hline
\end{tabular}

*Based on Chi Square NA: not applicable

Table 4:- Natal factors possibly associated with autism

\begin{tabular}{|c|c|c|c|c|c|c|}
\hline \multirow{3}{*}{ Characteristics } & \multicolumn{4}{|c|}{ Study group } & \multirow{3}{*}{$X^{2}$} & \multirow{3}{*}{$\mathrm{P}^{*}$} \\
\hline & \multicolumn{2}{|c|}{ Cases } & \multicolumn{2}{|c|}{ Controls } & & \\
\hline & No & $\%$ & No & $\%$ & & \\
\hline \multicolumn{5}{|l|}{ Mode of delivery: } & \multirow[b]{3}{*}{0.343} & \multirow[b]{3}{*}{0.558} \\
\hline Vaginal & 19 & $70.4 \%$ & 52 & $64.2 \%$ & & \\
\hline Caesarean & 8 & $29.6 \%$ & 29 & $35.8 \%$ & & \\
\hline \multicolumn{5}{|c|}{$\begin{array}{l}\text { Use of ventouse for vaginal } \\
\text { deliveries: }\end{array}$} & \multirow{3}{*}{ Fisher } & \multirow{3}{*}{0.988} \\
\hline Yes & 1 & $5.3 \%$ & 3 & $5.8 \%$ & & \\
\hline No & 18 & $94.7 \%$ & 49 & $94.2 \%$ & & \\
\hline
\end{tabular}




\begin{tabular}{|c|c|c|c|c|c|c|}
\hline $\begin{array}{l}\text { Received epid } \\
\text { during vaginc }\end{array}$ & & & & & \multirow{3}{*}{0.195} & \multirow{3}{*}{0.659} \\
\hline Yes & 2 & $10.5 \%$ & 8 & $15.7 \%$ & & \\
\hline No & 17 & $89.5 \%$ & 43 & $84.3 \%$ & & \\
\hline \multicolumn{5}{|c|}{$\begin{array}{l}\text { Type of anesthesia for } \\
\text { caesarean deliveries: }\end{array}$} & \multirow{3}{*}{ Fisher } & \multirow{3}{*}{0.154} \\
\hline Spinal & 2 & $25.0 \%$ & 15 & $51.7 \%$ & & \\
\hline General & 6 & $75.0 \%$ & 14 & $48.3 \%$ & & \\
\hline \multicolumn{5}{|c|}{ Fetal distress during labor: } & \multirow[b]{3}{*}{ Fisher } & \multirow[b]{3}{*}{0.060} \\
\hline Yes & 4 & $14.8 \%$ & 3 & $3.7 \%$ & & \\
\hline No & 23 & $85.2 \%$ & 78 & $96.3 \%$ & & \\
\hline \multicolumn{5}{|c|}{ Age of the baby at delivery: } & \multirow{4}{*}{2.602} & \multirow{4}{*}{0.272} \\
\hline$<37$ weeks & 1 & $3.7 \%$ & 7 & $8.8 \%$ & & \\
\hline 37-40 weeks & 19 & $70.4 \%$ & 62 & $77.5 \%$ & & \\
\hline$>40$ weeks & 7 & $25.9 \%$ & 11 & $13.8 \%$ & & \\
\hline
\end{tabular}

* Based on Chi Square

Table 5:- Postnatal factors possibly associated with autism

\begin{tabular}{|c|c|c|c|c|c|c|}
\hline \multirow{3}{*}{ Characteristics } & \multicolumn{4}{|c|}{ Study group } & \multirow{3}{*}{$X^{2}$} & \multirow{3}{*}{$\mathrm{P}^{*}$} \\
\hline & \multicolumn{2}{|c|}{ Cases } & \multicolumn{2}{|c|}{ Controls } & & \\
\hline & No & $\%$ & No & $\%$ & & \\
\hline \multicolumn{5}{|l|}{ Weight of the baby at delivery: } & \multirow{4}{*}{3.622} & \multirow{4}{*}{0.163} \\
\hline$<2.5 \mathrm{~kg}$ & 4 & $14.8 \%$ & 8 & $9.9 \%$ & & \\
\hline $2.5-<3.5 \mathrm{~kg}$ & 17 & $63.0 \%$ & 65 & $80.2 \%$ & & \\
\hline$>3.5 \mathrm{~kg}$ & 6 & $22.2 \%$ & 8 & $9.9 \%$ & & \\
\hline \multicolumn{5}{|l|}{ The baby needed ICU after delivery: } & \multirow[b]{3}{*}{ Fisher } & \multirow[b]{3}{*}{0.746} \\
\hline Yes & 4 & $14.8 \%$ & 10 & $12.3 \%$ & & \\
\hline No & 23 & $85.2 \%$ & 71 & $87.7 \%$ & & \\
\hline \multicolumn{5}{|c|}{ The baby discharged with his mother: } & \multirow[b]{3}{*}{ Fisher } & \multirow[b]{3}{*}{0.360} \\
\hline Yes & 21 & $77.8 \%$ & 70 & $86.4 \%$ & & \\
\hline No & 6 & $22.2 \%$ & 11 & $13.6 \%$ & & \\
\hline \multicolumn{5}{|l|}{ Type of feeding: } & \multirow[b]{4}{*}{2.315} & \multirow[b]{4}{*}{0.314} \\
\hline Breastfeeding & 4 & $14.8 \%$ & 20 & $24.7 \%$ & & \\
\hline Bottle feeding & 7 & $25.9 \%$ & 12 & $14.8 \%$ & & \\
\hline Both breast and bottle & 16 & $59.3 \%$ & 49 & $60.5 \%$ & & \\
\hline
\end{tabular}

* Based on Chi Square

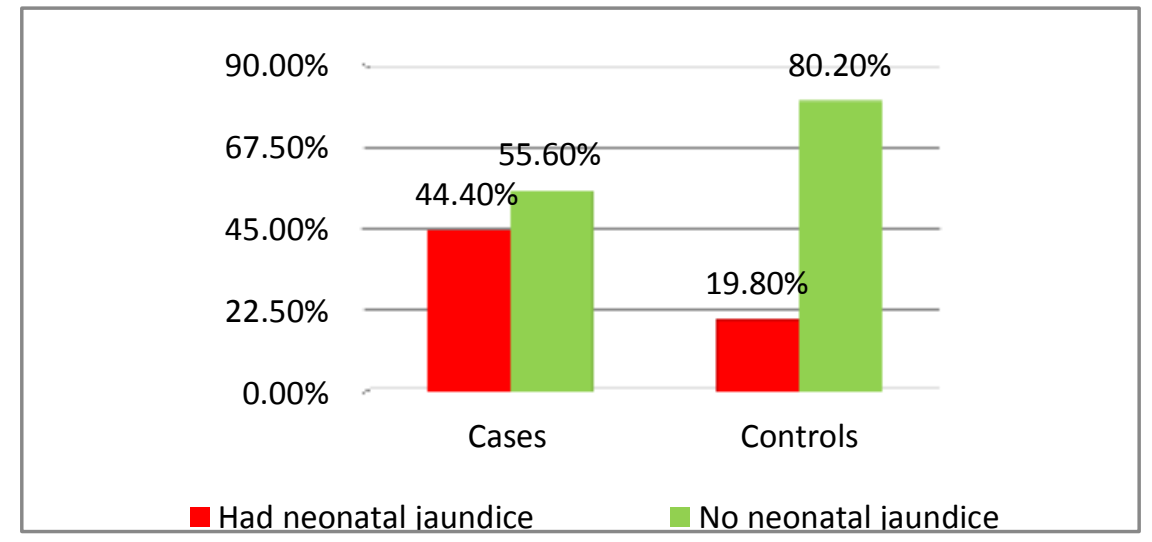

Chi square $=6.429, \mathrm{df}=1, \mathrm{p}=0.011$

Figure 2:- Differences in the occurrence of neonatal jaundice between cases and controls. 


\section{Discussion:-}

Most of the studied autistic patients were males $(77.8 \%)$, which comes in accordance with what was reported by Elsabbagh et al. that the male to female ratio ranges between 1.33 up to 16. (16) This phenomenon had been studied by Kreiser and White (17), who proposed that this difference be largely attributed to sociocultural influences that explain potential under-identification of ASD in females, because females are less likely to have unusual stereotyped and repetitive behaviors with increased prevalence of internalizing problems, in addition to gender inequities in searching for medical care.

Autism is usually diagnosed between 3 and 6 years of age, (18) before that age, the typical behavioral characteristics and social restrictions are not well developed and not easily recognized. (19) In this respect, most of our autistic patients had been diagnosed at the age between 3-4 years.

Most of our patients were from families with highly educated parents, and monthly income ranging between 5000$<10000$ SR. The link between socioeconomic status of the family and prevalence of autism had been discussed by several authors. For example, Juneja et al. (20), in India, reported that the most families of autistic children who are diagnosed in governmental institutes were from middle-class backgrounds. They explained this finding by the response bias because the higher socioeconomic families do not attend public facilities while the lower socioeconomic groups may not seek medical care except when their children become acutely ill.

In the same line, Tidmarsh and Volkmar (21) stated that in the past, a great proportion of families with autistic children were from the upper socioeconomic classes, just because families with lower socioeconomic classes lacked access to health care services, which means that the link between socioeconomic status and autism is a matter of accessibility to health care, this assumption is supported by what was found in Sweden, where there are universal health care and access to comprehensive approach services, they found that prevalence of autism among children decreased with increasing family socioeconomic status.

Almost one-half of the patients have one sibling, and mainly (48.1\%) they occupy the third or more ranks among their brothers and sisters. Tsai and Steward (22) described a trend toward an autistic child is more likely to be born in the 2nd half (i.e., 4th and above birth ranks) than in the 1 st half (i.e., 1st to 3rd birth ranks) among sibship size of four or more.

The impact of autistic children's birth order has been studied by Spiker et al. (23), who observed that repetitive behaviors occur more among first-born siblings, while second-born siblings were more likely classified as nonverbal and thus more impaired in this area.

The family history of autism was significantly more prevalent in our cases $(29.6 \%)$ than the controls $(6.2 \%) \mathrm{p}<0.05$, with an odds ratio (OR; 9.017, 95\% CI: 3.550-23.363). These findings agreed with those of several studies. El-Baz et al. (24) reported a positive Family history of autism among $16 \%$ of cases compared with only $1 \%$ of control subjects. Muhle et al. (25) suggested that families of individuals with autism tend to demonstrate a set of cognitive disorders that are not seen in other family groups.

Consanguinity of the parents was significantly more frequent in autistic patients than controls, which comes in accordance with what was found by Mamidala et al. (26), who reported that consanguinity increases the risk of autism with an odds ratio of 3.22; and may raise the possibility of recessively inherited genetic risk factors for autism. They noted that children born to consanguineous parents usually have a lower cognitive ability and social behavior, which are major issues related to autism.

Parental age is assumed to be associated with autism, the results of the researches in this area are mixing, for example, Reichenberg et al. (27) reported an association between advancing paternal age and risk of autism among their children. They concluded that offspring of 40 years men or older were 5.75 times more likely to have autism compared with offspring of men younger than 30 years.

Also, El-Baz et al. (24) found that older parental age (i.e., mother and/or father older than 35 years) at birth was found significantly higher among autistic than control children (23\% and $9.5 \%$, respectively). 
Collectively, Kolevzon et al. (28) found that advanced maternal and paternal age are associated with increased risk of autism spectrum disorders. Nevertheless, Puleo et al. (29) argued that the association between parental age and autism is significantly apparent in female offspring but not in males.

The current study showed that although a larger percentage of the cases than controls were born for relatively older mothers (Aged $\geq 30$ years) and older fathers aged more than 40 years $(33.3 \%)$, these differences were not statistically significant.

Our study revealed that, compared to the mothers of the control children, almost double of the mothers of the cases reported that they had been suffering from diseases such as diabetes mellitus, hypertension, psychological problems, gestational diabetes and hypothyroidism during pregnancy, compared to the mothers of the controls. However, these differences were not statistically significant.

These findings come in congruence with what was addressed by Alrehaili et al. (30), who reported that there was no significantly different prevalence of chronic diseases during pregnancy among mothers of children with autism spectrum disorder. Also, Hultman et al. (31) found no relationship between autism among children mothers with hypertensive disorders.

Findings of this study showed no difference in modes of delivery between cases and controls, type of anesthesia, birth weight, being post-term, fetal distress during labor, being discharged from the hospitals with their mothers, nor exclusively breastfed. Gardener et al. supports these findings (5), reported that there is no sufficient evidence to prove a significant impact of any of prenatal factors for autism etiology. Similarly, El-Baz et al. (24) found no significant differences between cases and controls regarding prenatal or natal factors.

Finally, the most prominent natal factor associated significantly with autism in the current study is neonatal jaundice with significantly higher percentage of cases than controls, and an odds ratio of 3.25. Similarly, El-Baz et al. (24) reported that neonatal jaundice was significantly higher among cases than controls $(\mathrm{p}<0.001)$. Maimburg and Vaeth (32) reported an almost fourfold increased risk for autism spectrum disorder among children who had hyperbilirubinemia after birth with an odds ratio of 3.7. This suggests that neonatal jaundice is an important risk factor for autism. They added that exposure to high serum bilirubin levels after birth might be the first sign of an underlying susceptibility to autism. More detailed information about the level of unconjugated bilirubin would be desirable in future studies.

As a limitation, parents' recall bias was highly probable during data collection. Although this study included all autistic children registered at Jeddah Autism Center, yet the sample size was quite limited. Therefore, a multicenter large-scale study must be directed to all diagnosed cases of autism spectrum disorder registered at all autism centers all-over the Saudi Arabia to perform an in-depth exploration of the magnitude and risk factors of autism.

For conclusion, the incidence of autism in Jeddah is higher among male children, which becomes diagnosed mainly between age of 3-4 years. Some characteristics are more associated with cases of autism, e.g., those related to the child's parents (e.g., consanguinity and older age), family history of autism, maternal factors (e.g., gestational diabetes, preeclampsia, and hypothyroidism), natal (e.g., natal fetal distress), and postnatal (e.g., occurrence of neonatal jaundice and lack of exclusive breastfeeding). However, differences are statistically significant to a positive family history of autism and occurrence of neonatal jaundice.

Therefore, a highly recommended that all children attending the well-baby clinics, (especially those with a positive family history of autism and/or history of occurrence of neonatal jaundice), should undergo repeated developmental screening for early detection of autism. Moreover, health education should be provided to parents of autistic children regarding care of their children. 


\section{References:-}

1. Global, regional, and national incidence, prevalence, and years lived with disability for 301 acute and chronic diseases and injuries in 188 countries, 1990-2013: a systematic analysis for the Global Burden of Disease Study 2013. Lancet 2015; 386(9995):743-800.

2. CDC | Data and Statistics | Autism Spectrum Disorder (ASD) | NCBDDD [Internet]. [cited 2016 Feb 9]. Available from: http://www.cdc.gov/ncbddd/autism/data.html

3. Koufaris C, Sismani C. Modulation of the genome and epigenome of individuals susceptible to autism by environmental risk factors. Int J Mol Sci [Internet]. 2015;16(4):8699-718.

4. Chaste P, Leboyer M. Autism risk factors: genes, environment, and gene-environment interactions. Dialogues Clin Neurosci 2012; 14(3):281-92.

5. Gardener H, Spiegelman D, Buka SL. Prenatal risk factors for autism: Comprehensive meta-analysis. British Journal of Psychiatry 2009; 195: 7-14.

6. Guinchat V, Thorsen P, Laurent C, Cans C, Bodeau N, Cohen D. Pre-, peri- and neonatal risk factors for autism. Acta Obstetricia et Gynecologica Scandinavica. 2012; 91: 287-300.

7. Rahbar MH, Samms-Vaughan M, Loveland KA, Pearson DA, Bressler J, Chen Z, et al. Maternal and paternal age are jointly associated with childhood autism in Jamaica. J Autism Dev Disord 2012; 42(9):1928-38.

8. Lampi KM, Lehtonen L, Tran PL, Suominen A, Lehti V, Banerjee PN, et al. Risk of autism spectrum disorders in low birth weight and small for gestational age infants. J Pediatr 2012; 161(5):830-836.

9. Zhang X, Lv C-C, Tian J, Miao R-J, Xi W, Hertz-Picciotto I, et al. Prenatal and perinatal risk factors for autism in China. J Autism Dev Disord 2010; 40(11):1311-21.

10. Lyall K, Schmidt RJ, Hertz-Picciotto I. Maternal lifestyle and environmental risk factors for autism spectrum disorders. Int J Epidemiol 2014; 43(2):443-64.

11. Salhia HO, Al-Nasser LA, Taher LS, Al-Khathaami AM, El-Metwally AA. Systemic review of the epidemiology of autism in Arab Gulf countries. Neurosciences (Riyadh) 2014;19(4):291-6.

12. Al-Farsi YM, Al-Sharbati MM, Waly MI, Al-Farsi OA, Al-Shafaee MA, Al-Khaduri MM, et al. Effect of suboptimal breast-feeding on occurrence of autism: a case-control study. Nutrition. 2012; 28:e27-e32.

13. Al-Salehi SM, Al-Hifthy EH, Ghaziuddin M. Autism in Saudi Arabia: presentation, clinical correlates and comorbidity. Transcult Psychiatry. 2009; 46:340-347.

14. Fombonne E. Epidemiology of pervasive developmental disorders. Pediatr Res, 2009; 65: 591.

15. Ozonoff S, Young GS, Carter A, et al. Recurrence risk for autism spectrum disorders: A Baby Siblings Research Consortium study. Pediatrics 2011; 128: e488.

16. Elsabbagh M, Divan G, Koh YJ, Kim YS, Kauchali S, Marcín C, et al. Global Prevalence of Autism and Other Pervasive Developmental Disorders. Autism Research. 2012;5(3):160-79.

17. Kreiser NL, White SW. ASD in Females: Are We Overstating the Gender Difference in Diagnosis? Clinical Child and Family Psychology Review. 2014;17(1):67-84.

18. Kalra V, Seth R, Sapra S. Autism - Experiences in a tertiary care hospital. The Indian Journal of Pediatrics. 2005;72(3):227-30.

19. Mandell DS, Novak MM, Zubritsky CD. Factors Associated With Age of Diagnosis Among Children With Autism Spectrum Disorders. Pediatrics. 2005;116(6):1480-6.

20. Juneja M, Mukherjee SB, Sharma S. A descriptive hospital based study of children with autism. Indian pediatrics. 2005; 42(5):453-8.

21. Tidmarsh L, Volkmar FR. Diagnosis and epidemiology of autism spectrum disorders. The Canadian Journal of Psychiatry / La Revue canadienne de psychiatrie. 2003; 48(8):517-25.

22. Tsai LY, Stewart MA. Etiological implication of maternal age and birth order in infantile autism. Journal of Autism and Developmental Disorders. 1983;13(1):57-65.

23. Spiker D, Lotspeich LJ, Dimiceli S, Szatmari P, Myers RM, Risch N. Birth Order Effects on Nonverbal IQ Scores in Autism Multiplex Families. Journal of Autism and Developmental Disorders. 2001;31(5):449-60.

24. El-Baz F, Ismael NA, El-Din SMN. Risk factors for autism: An Egyptian study. Egyptian Journal of Medical Human Genetics. 2011;12(1):31-8.

25. Muhle R, Trentacoste SV, Rapin I. The Genetics of Autism. Pediatrics 2004; 113(5):e472-86.

26. Mamidala MP, Kalikiri MK, Praveen Kumar PT V, Rajesh N, Vallamkonda OR, Rajesh V. Consanguinity in India and Its association with autism spectrum disorder. Autism Research. 2015;8(2):224-8.

27. Reichenberg A, Gross R, Weiser M, Bresnahan M, Silverman J, Harlap S, et al. Advancing paternal age and autism. Archives of general psychiatry. 2006;63(9):1026-32.

28. Kolevzon A, Gross R, Reichenberg A. Prenatal and perinatal risk factors for autism: a review and integration of findings. Archives of pediatrics \& adolescent medicine. 2007;161(4):326-33. 
29. Puleo CM, Schmeidler J, Reichenberg A, Kolevzon A, Soorya L V., Buxbaum JD, et al. Advancing paternal age and autism. Autism. 2012;16:367-80.

30. Alrehaili A, Ekhmimi Y, Almutairi A, Felemban A, Alrehaili B FW. The Prevalence and Relationship between Maternal Medical Conditions and Autism Spectrum Disorder. International Journal of Science and Research. 2017;6(2):1413-9.

31. Hultman CM., Sparén P, Cnattingius S. Perinatal Risk Factors for Infantile Autism. Epidemiology. 2002;13(4):417-23.

32. Maimburg RD, Vaeth M. Perinatal risk factors and infantile autism. Acta Psychiatrica Scandinavica. 2006;114(4):257-64. 